\title{
Solving the Early Earth - Moon Tungsten Riddle
}

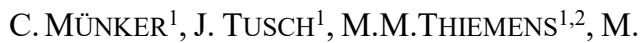 \\ FISCHER-GÖDDE ${ }^{1}$ \\ ${ }^{1}$ Institut für Geologie und Mineralogie, Universität zu Köln, \\ Germany (*correspondence: c.muenker@uni-koeln.de) \\ ${ }^{2}$ Laboratoire G-Time, Brussels, Belgium
}

Many lunar basalts and Archean rocks on Earth exhibit ${ }^{182} \mathrm{~W}$ anomalies, which are typically excesses. Two endmember models can explain these isotope anomalies: (1) missing late veneer contributions and (2) early silicate differentiation, possibly during the magma ocean stage. We evaluate these endmember models with respect to recently available $\mathrm{W}$ and $\mathrm{Ru}$ isotope data for terrestrial rocks, and elemental W systematics of lunar and early Archean rocks. As a first order observation, a compilation of available data for Archean assemblages show that combined ${ }^{182} \mathrm{~W}$ and HSE patterns of many Archean assemblages do not overlap a missing late veneer array, as defined by the most plausible delivery agents for Earth's characteristic volatile inventory, $\mathrm{CI}$ and $\mathrm{CM}$ chondrites [1]. Combining recently reported ${ }^{100} \mathrm{Ru}$ excesses with HSE patterns in Archean mantle rocks from SW Greenland [2] requires a scenario, where at least $60 \%$ of late veneer material was already added. Such quantities of late veneer, however, only contribute a third of the measured ${ }^{182} \mathrm{~W}$ excess (ca. $+12 \mathrm{ppm}$ ). Thus, early silicate differentiation is required to explain at least $2 / 3$ of the ${ }^{182} \mathrm{~W}$ excess, consistent with ${ }^{142} \mathrm{Nd}$ excesses found in rocks from SW Greenland and new ${ }^{182} \mathrm{~W}$ ${ }^{142} \mathrm{Nd}$ data for the Kaapvaal craton $[3,4]$. Similar to the early Archean rocks on Earth, on the Moon only ca. $50 \%$ of the ca. +26 ppm ${ }^{182} \mathrm{~W}$ excess can be explained by missing late veneer. A key parameter is also the lower W/Th of the lunar mantle that requires lunar core formation to have fractionated Hf/W on the Moon. Core formation therefore provides the most plausible explanation for at least $50 \%$ of the lunar ${ }^{182} \mathrm{~W}$ excess. Consequently, the Moon must have formed within the first 70 Myrs of the solar system [e.g., 5].

[1] Braukmüller et al. (2019) Nat. Geosc. 12, 564-568.

[2] Fischer Gödde et al. (2020) Nature, in press. [3] Tusch et al. (2020) this meeting. [4] Schneider et al. 2019 Chem. Geol 511, 152-177. [5] Thiemens et al. (2019) Nat. Geosc. 12, 696-700. 